\title{
O PROCESSO DE CONSTRUÇÃO DO OIIIIPe: QUESTÕES TEÓRICAS E METODOLÓGICAS
}

\author{
The OIIIIPe construction process: theorethical and methodological issues
}

El proceso de construcción del OIIIIPe: cuestiones teóricas y metodológicas

\author{
Mônica Pereira dos Santos* \\ Mayara Carvalho de Oliveira** \\ Raquel Batalha de Oliveira***
}

\begin{abstract}
Resumo
O Observatório Internacional de Inclusão, Interculturalidade e Inovação Pedagógica (OIIIIPe) busca desenvolver pesquisa, ensino e extensão em rede colaborativa, em níveis de graduação e pós-graduação, com o propósito de formar profissionais da educação que produzam saberes e práticas educativas críticas, transformadoras e orientadas pelos princípios de inclusão, interculturalidade e inovação pedagógica. Os conceitos abordados referem-se a um aporte teórico e prático, a partir do qual diversas relações precisam ser recontextualizadas, objetivando superar/minimizar a exclusão e promover a participação de todo indivíduo ou grupo que se encontre em situação de exclusão (SANTOS, 2013). Haja vista que se trata de uma pesquisa colaborativa em rede, diversas metodologias são utilizadas, tais como etnografia digital, pesquisa bibliográfica, documental e pesquisa colaborativa. Portanto, o trabalho constitui-se em um desafio, uma vez que, ao mesmo tempo em que amplia as possibilidades comunicacionais, apresenta barreiras que dificultam o acesso e a participação de algumas equipes. Diante do exposto, apresentaremos questões teóricas e metodológicas que permeiam as pesquisas do OIIIIPe, bem como os resultados oriundos dos primeiros instrumentos de coleta de dados elaborados e aplicados pelos pesquisadores.
\end{abstract}

PALAVRAS-CHAVE: Inclusão. Interculturalidade. Inovação pedagógica.

\begin{abstract}
The International Observatory of Inclusion, Interculturalism and Pedagogic Innovation (IOIIPI) seeks to develop research, teaching and extension in a collaborative network, at undergraduate and postgraduate levels, with the purpose of training education professionals who produce critical, transformative educational knowledge and practices which are guided by the principles of inclusion, interculturalism and pedagogical innovation. The discussed concepts refer to a theoretical and practical contribution, from which several relationships need to be recontextualized, aiming to overcome/minimize exclusion and to promote the participation of every individual or group that is in a situation of exclusion (SANTOS, 2013). Several methodologies are used, such as digital ethnography,
\end{abstract}

\footnotetext{
* Professora Associada da Faculdade de Educação da Universidade Federal do Rio de Janeiro/Linha de Inclusão, Ética e Interculturalidade. Presidente da Comissão Executiva do Fórum Permanente UFRJ Acessível e Inclusiva. $\mathrm{PhD}$ em Psicologia e Educação Especial pela Universidade de Londres. Fundadora e Coordenadora do Laboratório de Pesquisa, Estudos e Apoio à Participação e à Diversidade em Educação (LaPEADE/FE/UFRJ). E-mail: <moicapes@globo.com.br>.

** Licenciada em Letras - Português/Espanhol pela Universidade Federal do Rio de Janeiro. Mestranda em Educação pela Universidade Federal do Rio de Janeiro e membro do Laboratório de Pesquisa, Estudos e Apoio à Participação e à Diversidade em Educação (LaPEADE/FE/UFRJ).E-mail: <mayoliveira_05@yahoo.com.br>.

*** Licenciada em Ciências Biológicas pela Universidade Iguaçu. Especializada em Neuroeducação pela Universidade Estácio de Sá. Mestranda em Educação pela Universidade Federal do Rio de Janeiro e membro do Laboratório de Pesquisa, Estudos e Apoio à Participação e à Diversidade em Educação (LaPEADE/FE/UFRJ). Email:<raquelbatalha.o@gmail.com>.
} 
bibliographic documentary research, and collaborative research. Thus, the work constitutes a challenge, once at the same time that it broadens the communicational possibilities, it presents barriers that make difficult both the access and the participation of some teams. In view of the above, we will present theoretical and methodological questions that permeate the IOIIPI researches, as well as the results arisen from the first data collection instruments developed and applied by the researchers.

KEYWORDS: Inclusion. Interculturalism. Pedagogical innovation.

\section{Resumen}

El Observatorio Internacional de Inclusión, Interculturalidad e Innovación pedagógica (OIIIIPe) desarrolla la investigación, enseñanza y extensión en red colaborativa, en niveles de graduación y posgrado, con el objetivo de formar profesionales de la educación que produzcan saberes y prácticas educativas críticas, transformadoras y orientadas por los principios de inclusión, interculturalidad e innovación pedagógica. Los conceptos abordados se refieren a una base teórica y práctica, a partir del cual diversas relaciones necesitan ser cambiadas, objetivando superar/disminuir la exclusión y promover la participación de todo individuo o grupo que se encuentre en situación de exclusión (SANTOS, 2013). Diversas metodologías son utilizadas, tales como etnografía digital, investigación bibliográfica, documental e investigación colaborativa. De esta forma, el trabajo se constituye en un desafío, una vez que al mismo tiempo en que amplía las posibilidades comunicacionales, presenta impedimentos que dificultan el acceso y la participación de algunos equipos. Ante lo expuesto, presentaremos cuestiones teóricas y metodológicas que permean las investigaciones del OIIIIPe, así como los resultados oriundos de los primeros instrumentos de recolección de datos elaborados y aplicados por los investigadores.

PALABRAS CLAVE: Inclusión. Interculturalidad. Innovación pedagógica.

\section{INTRODUÇÃO}

O Observatório Internacional de Inclusão, Interculturalidade e Inovação Pedagógica (OIIIIPe) constitui-se, atualmente, em um desdobramento de uma das pesquisas que vêm sendo desenvolvidas pelo Laboratório de Pesquisa, Estudos e Apoio à Participação e à Diversidade em Educação (LaPEADE/FE/UFRJ). Desde 2003, o LaPEADE busca promover a participação e a diversidade em educação a partir das dimensões culturais, políticas e práticas (BOOTH; AINSCOW, 2011) da vida humana e social, com o intuito de minimizar os processos de exclusão verificados em projetos e diretrizes de instituições e sistemas educacionais nacionais e internacionais.

Em 2005, o Laboratório realizou o primeiro seminário internacional organizado e produzido pelo grupo de pesquisa, intitulado "Seminário Internacional de Inclusão em Educação: Universidade e Participação", o qual foi responsável pelo estreitamento dos laços entre pesquisadores brasileiros e estrangeiros e, consequentemente, deu início à primeira pesquisa internacional, chamada de "Culturas, Políticas e Práticas de Inclusão em Universidades: um foco na formação inicial de professores" (2007-2010). Inicialmente, a pesquisa contava com a participação de Brasil, Cabo Verde e Espanha (Córdoba e Sevilha) e teve duração de três anos, tendo sido finalizada no ano de 2010. Ao longo desse período, foram realizados estudos no tocante à concepção de estudantes do ensino superior acerca de inclusão/exclusão em sua formação, bem como análise dos documentos oficiais das universidades participantes da pesquisa. De igual modo, foi elaborado e analisado um questionário aplicado a estudantes do curso de Licenciatura das instituições, totalizando-se um total de $12 \%$ de respondentes das Faculdades de Educação das universidades. A pesquisa internacional gerou desdobramentos importantes na área da educação, mais especificamente na área de inclusão/exclusão em educação. 
Como resultado, foram produzidos artigos científicos e realizado o Seminário Internacional de Inclusão em Educação: Universidade e Participação II, em 2010, o qual propiciou o compartilhamento e a difusão de questões inerentes à pesquisa em educação, além de ter agregado novos pesquisadores e reafirmado o compromisso dos pesquisadores, até então, envolvidos com o projeto. A riqueza dos dados oriundos dos questionários e as questões que não puderam ser respondidas durante o tempo de investigação reacenderam o desejo de dar prosseguimento à pesquisa, o que resultou no projeto "Culturas, Políticas e Práticas de Inclusão em Educação Superior: as vozes dos formadores de professores” (2010-2013), cujo foco eram as percepções dos formadores de professores sobre os processos de inclusão e exclusão presentes nas universidades em que atuavam. Além das instituições de ensino superior que já integravam a pesquisa, houve adesão da equipe de Portugal, fator que contribuiu para que fosse atingida uma amostra de 221 professores participantes.

Em 2013, o LaPEADE realizou a terceira edição do seminário internacional, intitulado "Seminário Internacional de Inclusão em Educação: Universidade e Participação 3", em que foram apresentadas as novas frentes de pesquisas científicas e extensões do Laboratório, demais instituições de ensino superior brasileiras e estrangeiras. Tendo em vista que o seminário internacional é, fundamentalmente, fruto dos estudos e discussões levantadas ao longo dos anos de pesquisa, a cada edição se tornavam evidentes a importância e a necessidade de dar continuidade aos estudos sobre inclusão/exclusão no ensino superior, nos contextos nacionais e internacionais.

Em face do exposto, em 2015, com a articulação de novos horizontes de pesquisa e novos pesquisadores, a pesquisa internacional, em parceria com instituições públicas de educação e secretarias municipais e estaduais de educação, passou a se chamar Grupo Internacional de Inclusão em Educação (GRIInE), cujo objetivo era construir uma rede nacional e internacional de investigação-ação e de formação continuada sobre a temática de inclusão em educação, ${ }^{1}$ utilizando o Index para a Inclusão (BOOTH; AINSCOW, 2011). O referido projeto de pesquisa, no entanto, adquiriu ampla proporção, tendo sido transformado, posteriormente, em duas frentes de pesquisa distintas, mas complementares, o Núcleo de Estudos sobre Gestão e Inclusão em Educação (NUGInE) e o Observatório Internacional de Inclusão, Interculturalidade e Inovação Pedagógica (OIIIIPe), do qual iremos tratar neste artigo.

\section{Sobre o OIIIPe}

Atualmente, o OIIIIPe congrega cerca de 100 pesquisadores de 23 instituições, brasileiras e estrangeiras, a saber: Faculdade Municipal de Palhoça (FMP), Instituto Federal Catarinense (IFC), Universidade Católica de Maule (UCM-Chile), Universidade de Córdoba (UCO-Espanha), Universidades Federal e Estadual do Piauí (UFPI-UESPI), Universidade Federal do Ceará (UFC), Universidade Federal de Grandes Dourados (UFGD), Universidade Federal do Maranhão (UFMA), Universidades Federal de Ouro Preto e de Minas Gerais (UfopUFMG), Universidades Federal e Estadual do Rio de Janeiro (UFRJ-UERJ), Universidade Federal Fluminense (UFF), Universidade Federal do Sul da Bahia (UFSB), Universidade Estadual de São Paulo (Unesp-Bauru), Universidade de Cabo Verde (Uni-CV), Universidades Federal e Estadual do Amapá (UNIFAPp-UEAP), Instituto Federal do Amapá (IFAP),

\footnotetext{
${ }^{1}$ Referência ao projeto de pesquisa "Inclusão na Administração Pública: um estudo sobre o papel de uma escola de governo no desenvolvimento de culturas, políticas e práticas públicas mais inclusivas", de 2015, desenvolvido pelo Laboratório de Pesquisa, Estudos e Apoio à Participação e à Diversidade em Educação (LaPEADE/FE/UFRJ). Disponível em: 〈http://www.lapeade.com.br/publicacoes/pesquisas/Projeto_de_Pesquisa_IAP2015-2016.pdf>.
} 
Universidade Federal de Itajubá (UNIFEI), Universidade Pedagógica Nacional (UPN-México) e Universidade do Vale do Acaraú (UVA).

Se, a princípio, a pesquisa internacional contava com a participação de um número restrito de pesquisadores, hoje, em virtude da criação do Observatório Internacional, vem se constituindo em uma rede de colaboração complexa que, embora tenha mantido o foco na formação de educadores, incluiu, em seu bojo, não só a perspectiva da inclusão (BOOTH; AINSCOW, 2011; SANTOS, 2013, 2016), mas também da interculturalidade (FLEURI, 2001) e da inovação pedagógica (CUNHA, 2010; CÂNDIDO; SILVEIRA, 2013), que têm se mostrado categorias complementares importantes na discussão sobre inclusão em educação. Além disso, o Observatório trabalha com diversas metodologias e subprojetos de pesquisa, respeitando-se as demandas regionais de cada Instituição de Ensino Superior (IES) participante.

Nos últimos anos, tem-se constatado que as exclusões no ensino superior, acarretadas, muitas vezes, por práticas colonialistas, acontecem de variadas maneiras (veladas ou não), entre diferentes atores (discentes, docentes, gestão), desencadeando tensões que podem se converter em barreiras à participação e, consequentemente, ao desenvolvimento de culturas, políticas e práticas inclusivas (BOOTH; AINSCOW, 2011), interculturais e pedagogicamente inovadoras. Tais fenômenos vêm sendo observados por Santos et al. (2007) em seus estudos referentes à exclusão/inclusão no ensino superior nos contextos nacionais e internacionais, a partir dos quais verificou a existência dos fenômenos de exclusão, em diferentes níveis, na percepção e sentimento de alunos e professores.

De acordo com Santos (2016), inclusão não se restringe ao pensar e refletir sobre o grupo de excluídos, mas sobre a causa de sua exclusão. Nesse sentido, "exclusão é sempre causada pelo modo como nós, sociedade, lidamos com as características de cada sujeito, e também como a sociedade se estrutura em termos sociais, políticos e econômicos" (SANTOS, 2016, p. 28). No contexto do Observatório, é preciso considerar, portanto, a categoria de descolonialidade como premissa basilar para as perspectivas de inclusão, interculturalidade e inovação pedagógica, uma vez que as características de qualquer sujeito (cor, cultura, orientação sexual, gênero, religião, entre outras), em termos éticos e de direitos humanos, não podem ser utilizadas como justificativa para sua exclusão (SANTOS, 2016, p. 28).

A perspectiva intercultural, por sua vez, caracteriza-se pela diversidade de culturas em um mesmo espaço, onde se podem identificar as tensões e semelhanças, numa relação de respeito e valorização dos processos históricos e culturais existentes. Descolonialidade é entendida, portanto, a partir da assunção das diferenças como condição inerente ao avanço de concepções e práticas educacionais que propiciem a compreensão de tais processos em distintos contextos históricos, no sentido de refletir e repensar os padrões classificatórios e normatizantes em que ainda se insere o universo educacional. Isso porque a diferença se apresenta como tema central nos cursos de formação de educadores, de modo que é necessária a existência de um diálogo cujo intuito seja favorecer a redefinição de concepções de formação, de docência, de conhecimento, de ensino e aprendizagem, a partir da reinvenção da realidade apresentada pelos diversos coletivos.

No Brasil, a valorização da diversidade cultural tem sido abordada por políticas públicas que incentivam reformas curriculares, haja vista os fenômenos de racismo e de discriminação étnica e social presentes em nossa sociedade. Contudo, a operacionalização de tais políticas públicas permanece frágil (AKKARI; SANTIAGO, 2010), uma vez que a imagem de "democracia racial" brasileira acoberta "grande parte da conflitividade das relações em nosso contexto [...] enfraquecendo o enorme potencial que pode advir do confronto e da interpretação crítica entre diferentes grupos culturais" (FLEURI, 2001, p. 50). Nesse contexto, a perspectiva intercultural visa não só "conhecer - com a finalidade de orientar a prática pedagógica - os complexos itinerários de formação e produção cultural que percorrem contextos já fortemente 
miscigenados", mas também "proporcionar meios para promover a autoconsciência [...] em sujeitos que vivem em ambientes marginalizados" (FLEURI, 2001, p. 50), atuando como instrumento indispensável à prática educativa.

Considerando-se que é preciso articular teoria e prática e que os educadores são atoreschave no desenvolvimento de culturas, políticas e práticas de inclusão (e exclusão) e interculturalidade, faz-se imprescindível evidenciar os saberes-fazeres que fomentam a descolonização das diferenças culturais nos distintos contextos educacionais de nível superior. Em virtude disso, as práticas educativas devem ser inovadoras, "compreendidas como aquelas que rompem com o paradigma da racionalidade técnica, baseada, entre outros aspectos, em lógica disciplinar e na pura transmissão de conhecimentos científicos". ${ }^{2}$

Tais inovações ocorrem a partir de um posicionamento crítico, explícito ou não, ou, ainda, de uma ruptura paradigmática ou uma descontinuidade, ante as práticas pedagógicas tradicionais prevalentes nas culturas dos contextos de ensino (CÂNDIDO; SILVEIRA, 2013, p. 4). Nesse sentido, inovação pedagógica está relacionada aos contextos que não são habituais no que concerne à aprendizagem, ou seja, mudanças que ocorrem em práticas pedagógicas conservadoras. Em outras palavras, refere-se a práticas formativas inovadoras que pressuponham a inovação curricular - no sentido de reconhecer e respeitar as diferenças, o desenvolvimento de posturas investigativas, uma ruptura paradigmática - que vise "o reconhecimento de outras formas de produção de saberes, incorporando a dimensão sóciohistórica do conhecimento" (CUNHA, 2010, p. 24) e a legitimação de um currículo pluriuniversitário.

As perspectivas de inclusão, interculturalidade e inovação pedagógica apresentadas dizem respeito, portanto, às práticas formativas que almejam rupturas paradigmáticas, tais como reconfiguração e descolonialidade de saberes, legitimação de novas (outras) formas de conhecimento, protagonismo, participação, desinstitucionalização (continuidade e descontinuidade das racionalidades educacionais), entre outras, com o intuito de promover atividades que permitam aos educadores repensar ou, até mesmo, "reinventar" não só o conhecimento como a si próprios.

Conquanto o Observatório busca problematizar concepções culturais colonialistas, por vezes subestimadas no ambiente acadêmico, diferentes abordagens metodológicas vêm sendo trabalhadas no decorrer da pesquisa, a saber: (i) etnografia digital (POLIVANOV, 2013; HINE, 2000; HORST; MILLER, 2012); (ii) pesquisa bibliográfica (FONSECA, 2002); (iii) pesquisa documental (FONSECA, 2002; CELLARD, 2008; FIGUEIREDO, 2007); e (iv) pesquisa colaborativa (DESGAGNÉ, 2007). Portanto, além de atender, de forma mais abrangente, às demandas institucionais, a diversidade de metodologias possibilita que os pesquisadores identifiquem, reflitam criticamente e, futuramente, adotem mudanças institucionais que estimulem relações orientadas pela inclusão, pela interculturalidade e pela inovação pedagógica.

Tendo em vista os estudos de Polivanov (2013), quando pensamos em etnografia digital, ocorrem-nos algumas questões: pode-se considerar o ciberespaço efetivamente um lugar? Podese falar em etnografia quando se trata de ambientes digitais, nos quais há sempre a mediação entre o pesquisador e o pesquisado? De acordo com Hine (2000), o que diferencia as pesquisas com enfoques digitais são as terminologias propostas para dar conta dessa "adaptação" do método etnográfico para o mundo virtual e suas implicações.

\footnotetext{
${ }^{2}$ Referência ao projeto de pesquisa intitulado "Formação de educadores: inclusão, interculturalidade e inovação pedagógica em contextos internacionais de ensino superior", em desenvolvimento, desde 2015, pelo Observatório Internacional de Inclusão, Interculturalidade e Inovação Pedagógica (OIIIIPe).
} 
Desse modo, partindo-se do pressuposto de que etnografia é a ciência da descrição cultural (GEERTZ, 2008), a etnografia digital busca compreender o comportamento de determinado grupo de pessoas dentro do ambiente virtual. Em outras palavras, a etnografia oferece uma narrativa sobre um grupo de pessoas ou comunidade, construída por meio da reconstrução e interpretação dos dados coletados. Além disso, a etnografia digital visa realizar uma aproximação entre o mundo real e o mundo virtual, uma vez que os ambientes online e offline estão entrelaçados e, portanto, as informações coletadas digitalmente são, também, culturalmente construídas (HORST; MILLER, 2012). Para tanto, em um primeiro momento, os instrumentos de coleta de dados utilizados foram questionário e entrevista.

No que concerne às pesquisas bibliográfica e documental, pode-se dizer que trilham o mesmo caminho (FONSECA, 2002). De acordo com a autora, a pesquisa bibliográfica é realizada a partir do levantamento de referências teóricas previamente analisadas e publicadas, por meios escritos e/ou eletrônicos, enquanto a pesquisa documental recorre a fontes mais diversificadas, isto é, fontes sem tratamento analítico, como jornais, revistas, documentos oficiais, entre outros (FONSECA, 2002, p. 32). A esse respeito, Cellard (2008) reitera que o uso de documentos em pesquisa permite acrescer a dimensão do tempo à compreensão social, de modo que a análise documental propicia a observação do processo de maturação de indivíduos, grupos, comportamentos, entre outros.

Se, por um lado, a pesquisa bibliográfica valoriza a produção do conhecimento, uma vez que direciona o foco e olhar para objetos de interesse pouco ou nunca estudados, a pesquisa documental, de outro, atua como fonte complementar, visto que oferece riqueza de informações, ampliando o entendimento de objetos cuja compreensão necessita de contextualização histórica e sociocultural. Isso posto, as pesquisas bibliográfica e documental são consideradas ponto de partida fundamental para a construção desse projeto, haja vista a necessidade de conhecer não só outras produções científicas essenciais para consolidação do objeto de estudo, como também os documentos são fontes de informação, indicação e esclarecimentos capazes de elucidar determinadas questões e evidenciar outras (FIGUEIREDO, 2007).

Por se tratar de um projeto que vem construindo uma rede de colaboração intercontinental, além dos métodos de pesquisa supracitados, o Observatório trabalha, igualmente, com a pesquisa colaborativa. De acordo com Desgagné (2007, p. 8), “a ideia de colaboração entre pesquisadores e docentes práticos [...] provém da constatação do distanciamento existente entre o mundo do exercício profissional e o da pesquisa que pretende esclarecê-lo", uma vez que é comum que os pesquisadores determinem um lócus de pesquisa, apliquem seus instrumentos, coletem os dados e não apresentem uma devolutiva aos "sujeitos" da investigação.

Tal prática contribui para o distanciamento entre a universidade e a escola, pois o conhecimento assim construído não auxilia o professor a lidar com a complexidade das situações educativas com que se confronta no dia a dia (DESGAGNÉ, 2007)). Ademais, é possível afirmar que o distanciamento também está presente dentro da própria universidade (ou das próprias universidades), a partir do momento em que os pesquisadores se encerram em suas pesquisas e não compartilham experiências com seus pares, por exemplo, ou, ainda, quando a gestão (reitorias, diretorias, coordenadorias) não toma conhecimento das atividades realizadas pelos pesquisadores dentro de suas instituições.

A pesquisa colaborativa pretende, portanto, romper com essa prática, visto que objetiva combinar, em uma mesma atividade, o ensino e a pesquisa mediante uma coconstrução que favorece tanto os pesquisadores quanto os "sujeitos" da investigação, os quais se tornam "atores sociais competentes", isto é, atores que desempenham um "controle reflexivo" sobre seu contexto profissional (DESGAGNÉ, 2007, p. 23). No âmbito da universidade, a pesquisa colaborativa permite que os docentes, de maneira cooperativa, contribuam ativamente para a 
construção do conhecimento, reconhecendo a necessidade de administrar sua própria formação, considerando, para tanto, as estruturas organizacionais (pesquisadores, docentes, discentes e gestão) responsáveis pelo planejamento de políticas para a instituição pesquisada.

\section{Primeiros resultados}

A diversidade metodológica com que o Observatório trabalha é uma faca de dois gumes, pois, ainda que as inovações tecnológicas tenham ampliado as possibilidades comunicacionais, permitindo, assim, maior entrosamento entre os membros de diferentes regiões e/ou países, ao mesmo tempo representa um desafio (a ser superado) para algumas equipes do projeto, uma vez que restrições no manuseio de plataformas digitais, por exemplo, geram barreiras à participação e, consequentemente, exclusão de alguns membros. Tais fatores não podem ser menosprezados no momento da análise dos dados.

Ao longo do ano de 2016, o foco principal foi o delineamento do novo projeto de pesquisa, a partir de análise bibliográfica e documental. Com universidades públicas gerenciadas por diferentes esferas do Poder Executivo (municipal, estadual e federal) pertencentes a vários Estados do Brasil, e também a outros países, a compreensão da contextualização histórica e cultural, bem como o conhecimento das estruturas administrativas e acadêmicas de cada instituição participante, constituíram-se como um dos pilares desta pesquisa. Para tanto, foi realizada uma análise documental dos arquivos oficiais das IES participantes, a saber: Estatutos, Diretrizes, Decretos, Plano de Desenvolvimento Institucional (PDI), Lei de Diretrizes e Bases (LDB), Plano Nacional de Educação (PNE), entre outros, com o intuito de levantar dados sobre políticas e ações de inclusão, interculturalidade e inovação pedagógica existentes.

Verificou-se que esses temas ainda são pouco explorados e se apresentam de maneira incipiente. Ademais, os conceitos sobre inclusão, interculturalidade e inovação pedagógica são manifestados de formas diversas e, muitas vezes, homônimas. As constatações da análise documental realizada em 2016 desencadearam na formulação de um questionário direcionado às equipes gestoras das instituições participantes do Observatório, com o objetivo de levantar as concepções acerca dos conceitos de inclusão, interculturalidade e inovação pedagógica, mapear propostas de ação e experiências sobre tais conceitos no tocante à formação de educadores e identificar dispositivos colonizadores nas relações que permeiam o cotidiano das referidas universidades.

Durante o ano de 2017, todas as equipes envolvidas iniciaram a aplicação do questionário em suas instituições. No entanto, foram identificados alguns entraves no desenvolvimento desta ação, por exemplo, o acesso aos gestores, público-alvo da pesquisa. A princípio, a comunicação foi feita via e-mails institucionais e, inclusive, pessoais. Contudo, dada a ausência de respostas, optou-se por agendar uma entrevista com os gestores. Todos os esforços foram feitos no intuito de conseguir uma amostra significativa na coleta de dados. Essa é uma etapa ainda não concluída do trabalho. A previsão é de terminá-la até o fím de 2018.

Por se constituir como rede colaborativa e com grande diversidade de pessoas, lugares, culturas e saberes, e tendo ampliado o número de pesquisadores participantes de forma considerável, foi elaborado coletivamente, ao final do primeiro semestre de 2017, um questionário (com 28 perguntas), cujo intuito foi conhecer melhor os pesquisadores integrantes da pesquisa, bem como suas percepções acerca do trabalho que vem sendo realizado desde 2016. Dentre as perguntas havia questões de cunho pessoal, tais como idade, estado civil, nacionalidade, gênero, raça, orientação sexual e religião, e questões de caráter acadêmico e 
profissional, como instituição a que pertence, cargo ou função, formação, número de orientandos (na totalidade e que integram a pesquisa), participação, ações desenvolvidas na pesquisa e de que forma se articulam com os objetivos do projeto, oportunidades e desafios da pesquisa. Os dados recolhidos foram analisados e categorizados.

O questionário foi divulgado durante as reuniões virtuais e presenciais do Observatório, tendo sido disponibilizado em plataforma digital acessível a todos e compartilhado diversas vezes por $e$-mail, e, até o presente momento, foram obtidas 32 respostas. Dos dados coletados constatou-se uma diversidade de respostas entre os Estados brasileiros e países integrantes do projeto. Participaram pesquisadores do Amapá $(9,68 \%)$, Ceará $(3,2 \%)$, Chile $(6,45 \%)$, Cabo Verde (12,9\%), Distrito Federal (3,23\%), Espanha (3,23\%), Maranhão (3,23\%), México $(3,23 \%)$, Minas Gerais $(9,68 \%)$, Rio de Janeiro (22,58\%), São Paulo (9,68\%), Santa Catarina $(3,23 \%)$ e Pará $(3,23 \%)$.

De modo geral, a maioria dos respondentes possui entre 30 e 60 anos, sendo $35 \%$ com idades entre 41 e 50 anos, feminina $(77,42 \%)$, branca $(50 \%)$, heterossexual $(70,37 \%)$, possui filhos $(59,38 \%)$ com idades entre $16-20$ anos $(29,63 \%)$, católica $(41,94 \%)$ ou não possui religião $(32,26 \%)$. No que diz respeito à pesquisa, a maioria foi convidada $(50 \%)$, ingressou no ano de 2016 (46,88\%) e são docentes (62,5\%) com Graduações e Pós-Graduações diversas, a saber: Graduação (100\%), sendo 34,38\% em Pedagogia e 16,63\% em Ciências Sociais; Mestrado Profissional (18,75\%), sendo 33,33\% em Planejamento e Políticas Públicas; Mestrado Acadêmico (75\%), sendo 62,5\% em Educação; e Doutorado (78,13\%), sendo 40\% em Educação.

Dos respondentes a maioria possui 2 ou 3 orientandos de Graduação $(13,79 \%)$ ou não possui nenhum (13,79\%) e cerca de 2 a 5 orientandos de Pós-Graduação $(64,29 \%)$, dos quais a maior parte não possui nenhum vínculo com a pesquisa do Observatório (75\%). No que concerne às ações desenvolvidas pelos pesquisadores no OIIIIPe, o número de respostas foi bastante diversificado. Dentre as respostas apresentadas a maioria declarou participar das reuniões $(46,88 \%)$, levantar dados $(25 \%)$, produzir ciência $(21,88 \%)$, elaborar o projeto $(18,75 \%)$ e executar a pesquisa $(15,63 \%)$, afirmando que tais ações se articulam ao objetivo geral do projeto a partir dos conceitos $(29,63 \%)$ e da própria pesquisa $(22,22 \%)$ e aos objetivos específicos a partir do uso das categorias como eixos norteadores de questões (30\%).

Quando perguntados sobre a criação de alguma política institucional de inclusão, interculuralidade ou inovação pedagógica que tenha sido produzida em sua instituição após sua entrada no Observatório, a maioria afirmou que nenhuma nova política havia sido criada $(50 \%)$ ou que não tinha conhecimento desse tópico $(10,71 \%)$. Com relação a produções científicas, concernentes ao OIIIIPe, desenvolvidas pelos pesquisadores, a maioria mencionou não ter realizado nenhuma $(30,77 \%)$ ou ter participado de eventos $(30,77 \%)$, seguida de escrita de artigos $(26,92 \%)$. Sobre a participação na pesquisa, grande parte declarou que a considera fraca e/ou tímida (33,33\%), ao mesmo tempo em que boa parte dos demais, 30\%, a considerou atuante e/ou positiva.

Por último, foi perguntado aos pesquisadores que oportunidades e desafios o OIIIIPe havia representado, até o presente momento, para eles. Novamente, as respostas dadas foram diversificadas. No quesito oportunidade, a maioria declarou como relevante a formação de uma rede de colaboração $(37,93 \%)$, bem como a troca de conhecimentos $(31,3 \%)$, a oportunidade de conhecimento de outros trabalhos $(24,14 \%)$ e estar em uma pesquisa internacional $(20,69 \%)$. Os desafios apresentados foram muitos, a saber: fortalecimento do trabalho em grupo $(26,67 \%)$, participação na pesquisa (16,67\%), articulação entre conhecimento e prática (10\%), comunicação (10\%), ampliação do conhecimento (10\%), compreensão dos objetivos da pesquisa $(6,67 \%)$, tempo e espaço para a realização da pesquisa $(6,67 \%)$ e, com 3,33\% cada, articulação com sua própria instituição de ensino superior, cumprimento de prazos, diversidade 
de contextos, fuso horário, investir na pesquisa, participação nas discussões e organização/logística da pesquisa.

\section{CONSIDERAÇÕES}

Os dados apresentados reiteram as dificuldades comunicacionais e, consequentemente, de participação de algumas equipes do Observatório, apontadas anteriormente. No momento da elaboração do projeto, reconheceu-se que a distância física entre as instituições nacionais e internacionais seria um entrave para as reuniões presenciais e discussões necessárias para o desenvolvimento da pesquisa, de modo que vem sendo feito uso dos recursos tecnológicos de comunicação a distância e, portanto, de diferentes abordagens metodológicas. No entanto, a despeito disso, as dificuldades comunicacionais se intensificam na medida em que os próprios recursos tecnológicos, antes pensados como facilitadores, têm se convertido em barreiras à participação de muitos pesquisadores.

A partir da análise dos questionários, percebeu-se que as barreiras tecnológicas influenciam diretamente não só na (não) participação de algumas equipes, mas também no (não) entendimento dos objetivos da pesquisa, o que gera desdobramentos negativos como a ainda baixa incidência de produção científica do Observatório e a dificuldade no fortalecimento do trabalho colaborativo. Esse dado é grave, considerando-se que um dos objetivos da pesquisa internacional é a construção de uma rede de colaboração acerca das temáticas expostas neste artigo. Além disso, os questionários revelaram que a maioria dos respondentes não possui nenhum orientando de graduação ou pós-graduação atuando na pesquisa, o que se justifica na medida em que se observam as dificuldades de participação, propiciadas pelo não entendimento da pesquisa, pela dificuldade de articulação de teoria e prática, ou, ainda, por questões institucionais e, inclusive, de organização da própria pesquisa.

Outra questão relevante diz respeito à constituição da própria equipe do Observatório. Os dados pessoais levantados reafirmam, em certa medida, a identidade feminina, branca, heterossexual e católica presente nas instituições de ensino superior, especialmente nas faculdades de educação. $\mathrm{O}$ fato de a maioria dos respondentes ser docentes doutoras e doutores também contribui para a reafirmação da elitização e hierarquização da pesquisa científica. Tais fatores possibilitam a reflexão a respeito da composição da equipe de pesquisadores, tendo em vista que o objetivo principal do projeto é, fundamentalmente, investigar os dispositivos colonizadores que permeiam os espaços de formação de professores.

Embora o questionário para os pesquisadores tenha sido elaborado apenas no ano de 2017, os entraves comunicacionais vêm sendo observados desde o início da pesquisa, de modo que foi solicitado aos pesquisadores, ao final de 2016, que realizassem uma avaliação dos pontos positivos e barreiras encontradas, bem como sugestões para o ano seguinte. À época, o Observatório contava com a participação de cerca de 70 pesquisadores, dentre os quais apenas quatro realizaram a avaliação - resultado que reitera, novamente, o desafio que tem sido a comunicação entre as equipes.

Dentre os pontos positivos apontados destacaram-se o fortalecimento institucional e a ampliação e consolidação da rede de colaboração (observados, também, no questionário aplicado em 2017). Como barreiras, foram ressaltadas as dificuldades de conectividade e utilização das plataformas online para realização dos encontros, bem como ausência de muitos membros durante as reuniões virtuais mensais e dificuldades de articulação entre os membros para consolidação da pesquisa local, isto é, entre os próprios pesquisadores de determinada equipe/região. Em virtude disso, as sugestões para o ano seguinte versaram sobre a necessidade 
de maior participação de, pelo menos, um membro das equipes, a criação de um tutorial para otimizar as reuniões em tempo real e aprimoramento do trabalho dos mediadores, o fortalecimento da comunicação entre os membros e a necessidade de descentralização das atividades do Observatório.

Pode-se dizer que o resultado da primeira avaliação das equipes foi paradoxal. Em primeiro lugar, ao mesmo tempo em que os pesquisadores ressaltaram o fortalecimento institucional e a consolidação da rede de colaboração, o baixo quantitativo de respondentes evidencia as dificuldades não só comunicacionais, mas também de participação dos membros das equipes. Em segundo lugar, percebeu-se um desejo de que as atividades do Observatório fossem mais bem divididas entre as equipes, uma vez que se trata de uma rede de colaboração, ainda que haja uma equipe coordenadora. No entanto, apesar da sugestão da criação de um tutorial para otimização das reuniões, por exemplo, não houve, ao longo do ano de 2017, nenhuma iniciativa por parte de outra equipe para a execução dessa tarefa.

É preciso ressaltar, entretanto, que, durante o ano de 2017, houve maior participação das equipes não só durante as reuniões, mas para a realização das atividades do Observatório. Foi acordado entre os membros que aconteceria uma reunião presencial, a cada semestre, em uma instituição diferente, a fim de que os pesquisadores tivessem oportunidade não só de estreitar os laços, mas também de compartilhar as experiências e o desenvolvimento das atividades e trabalhos inerentes ao Observatório. É possível afirmar, por conseguinte, que houve ampliação da rede de colaboração (ainda que não tenha sido percebida por alguns membros das equipes) e tentativas de fortalecimento da comunicação entre os pesquisadores. Ademais, a rotatividade de equipes anfitriãs para os encontros presenciais (e também virtuais) contribuiu para a descentralização de algumas atividades da equipe coordenadora.

Apesar de o quantitativo de respondentes ter sido baixo, ainda assim foi consideravelmente maior do que o realizado no ano de 2016. Isso ocorreu muito em razão da insistência, por parte da equipe coordenadora, para a realização dessa pesquisa, uma vez que os dados oriundos dos questionários são relevantes para o desenvolvimento do projeto. É por meio deles que os pesquisadores podem conhecer, de maneira clara e objetiva, a realidade com que trabalham as demais equipes e promover, conjuntamente, alternativas eficazes para melhor atender às demandas apresentadas (como as dificuldades tecnológicas e comunicacionais), levando em conta os princípios de inclusão, interculturalidade e inovação pedagógica que requerem participação plena de todo e qualquer indivíduo em todos os âmbitos sociais.

Levando-se em conta o objetivo geral da pesquisa, isto é, investigar contradições e perspectivas emergentes em propostas e experiências de inclusão, interculturalidade e inovação pedagógica voltadas para a formação de professores nos contextos universitários nacionais e internacionais, pode-se asseverar que a análise das práticas pedagógicas e diretrizes institucionais, inclusive das próprias equipes de pesquisadores, tem sido relevante e enriquecedora, tanto academicamente quanto para a construção de valores que contribuam para um mundo mais justo e com menos desigualdade. Desenvolver uma pesquisa em rede colaborativa revelou-se um imenso desafio. Na medida em que a investigação do Observatório avança, percebe-se que vem se constituindo em um exercício permanente de reflexão não só acerca dos conceitos supracitados, mas de sua própria organização e, consequentemente, da atuação dos pesquisadores que dela participam. Definir e ajustar os instrumentos de trabalho utilizados ao longo das ações determinadas pelo grupo, ouvir todos os participantes igualmente, acolher os diversos olhares e manter um espaço de respeito à diversidade têm sido, portanto, essenciais para a reflexão dos processos de inclusão.

Em virtude do exposto, a expectativa é a de que, nos próximos anos, o trabalho em equipe se fortaleça e auxilie na consolidação da rede de colaboração. O primeiro grande desafio para que isso aconteça são as restrições no manuseio de plataformas digitais - fator que gera a 
exclusão de alguns membros e intensifica as dificuldades comunicacionais -, de modo que, além das reuniões de estudo e análise dos dados da pesquisa, haverá um esforço para a criação de tutoriais para otimização das reuniões e manuseio das plataformas digitais utilizadas pelo Observatório. Portanto, espera-se estimular o envolvimento das equipes com as atividades de pesquisa para que encontrem tempo em suas agendas e se sintam confortáveis em participar das discussões. Ademais, a construção deste dossiê é o primeiro passo para aumentar a produção científica da pesquisa, haja vista o trabalho de articulação realizado por todas as equipes para elaborá-lo.

\section{REFERÊNCIAS}

AKKARI, A.; SANTIAGO, S. A gestão da diversidade cultural no contexto educacional brasileiro. Revista Educação em Questão, Natal, v. 38, n. 24, p. 9-33, maio-ago. 2010. Disponível em: <https://periodicos.ufrn.br/educacaoemquestao/article/view/4025/3292>. Acesso em: 24 jan. 2018.

BOOTH, T.; AINSCOW, M. Index para a inclusão: desenvolvendo a aprendizagem e a participação na escola. Tradução de Mônica Pereira dos Santos. Produzido pelo Laboratório de Pesquisa, Estudos e Apoio à Participação e à Diversidade em Educação - LaPEADE, FE-UFRJ. 3. ed. Rio de Janeiro: Unesco/CSIE, 2011. Disponível em: 〈http://www.lapeade.com.br〉. Acesso em: 23 jan. 2018.

CÂNDIDO, F. F.; SILVEIRA, S. M. P. Inovação pedagógica: novas formas de relacionamento e atuação na aprendizagem significativa, 2013. Disponível em: <http://www.abpprs.com.br/site/inovacao-pedagogica.pdf>. Acesso em: 23 jan. 2018.

CELLARD, A. A análise documental. In: POUPART, J. et al. A pesquisa qualitativa: enfoques epistemológicos e metodológicos. Petrópolis: Vozes, 2008.

CUNHA, M. I. O professor universitário na transição de paradigmas. 3. ed. Araraquara: Junqueira \& Marin Editores, 2010.

DESGAGNÉ, S. O conceito de pesquisa colaborativa: a ideia de uma aproximação entre pesquisadores universitários e pesquisadores práticos. Tradução de Adir Luiz Ferreira e Margarete Vale Sousa. Revista Educação e Questão, Natal, v. 29, n. 15, p. 7-35, maio-ago. $2007 . \quad$ Disponível em: <https://periodicos.ufrn.br/educacaoemquestao/article/view/4443/3629>. Acesso em: 16 jan. 2018.

FIGUEIREDO, N.M.A. Método e metodologia na pesquisa científica. 2. ed. São Caetano do Sul: Yendis, 2007. 
FLEURI, R. M. Desafios à educação intercultural no Brasil. Revista Educação, Sociedade e Cultura, n. 16, p. 45-62, 2001. Disponível em: <http://www.fpce.up.pt/ciie/revistaesc/ESC16/16-2.pdf>. Acesso em: 23 jan. 2018.

FONSECA, J. J. Metodologia da pesquisa científica. Fortaleza: UEC, 2002. Apostila.

GEERTZ, C. A interpretação das culturas. Rio de Janeiro: LTC, 2008.

HINE, Christine. Virtual ethnography. London: Sage Publications, 2000.

HORST, H. A.; MILLER, D. The digital and the human: a prospectus for digital anthropology. London: Berg Publications, 2012.

POLIVANOV, B. Etnografia virtual, netnografia ou apenas etnografia? Implicações dos conceitos. <https://portalrevistas.ucb.br/index.php/esf/article/view/4621/3243>. Acesso em: 16 jan. 2018.

SANTOS, Mônica Pereira dos. Dialogando sobre Inclusão em Educação: Contando casos (e descasos). Curitiba: CRV, 2013.

SANTOS, Mônica Pereira dos (Org.). Dossiê: "Da inclusão que temos à inclusão que queremos". Rio de Janeiro: Abrace Um Aluno Escritor, 2016.

Recebido em: 06/09/2017

Aceito em: 25/01/2018 